\title{
Gastropod landing, utilisation, and trade in India: A case study from Kollam, India
}

\author{
Shyam S. Salim*, I. Jagadis, V. Venkatesan, M. Ramees Rahman and M. Nashad1 \\ ICAR-Central Marine Fisheries Research Institute, Kochi-682018, Kerala. \\ `Nansen Environmental Research Centre India, Kochi-682016, Kerala. \\ *Correspondence e-mail: shyam.icar@gmail.com
}

Received: 11 Dec 2015, Accepted: 20 Dec 2016, Published: 15 Mar 2017

Original Article

\begin{abstract}
Gastropods used both for decorative and edible purposes are a valuable resource along the east and west coast of India and the Andaman \& Nicobar Islands. Even though the molluscan production in India was comparatively insignificant in earlier times, it increased due to the demand for edible as well as ornamental gastropods from around the globe coupled with their importance in generating additional income as a bycatch. The Shakthikulangara and Neendakara landing centres of the Kollam district of Kerala ranks among the major gastropod landing centres along the west coast of India. Based on the cost and earnings analysed from the primary data collected from Shakthikulangara and Neendakara area, various productivity ratios are analysed which indicates that the fishing for gastropods registered a shift in operations from harvesting as a by-catch resource to targeted fishing. The study reveals the scope of gastropod fishery in Kerala as well as the lack of shellcraft industry in the state. Also, the reduced availability of gastropods due to the extensive exploitation is investigated.
\end{abstract}

Keywords: Gastropod, fishery, Babylonia zeylanica, Babylonia spirata, shell craft industry, operculum, whelks.

\section{Introduction}

Molluscs are the second most diverse animal groups, next to insects. Gastropod constitute a large and highly diversified class within the phylum Mollusca, with a single piece spirally twisted shell. Almost 3271 species of molluscs were reported along the Indian coast which belongs to 220 families and 591 genera, including about 1900 species of gastropods (Appukuttan, 1996). Gastropods are a valuable resource along the east and west coast of India and the Andaman and Nicobar Islands. Gastropods are used both for decorative and edible purposes. James Hornell, the British biologist has much described the commercial importance of Indian molluscs in his reports published from 1905 to 1951 (Hornell, 1909, 1949, 1951). The Shakthikulangara and Neendakara landing centres of the Kollam district of Kerala state ranks among the major gastropod landing centres along the West coast of India. An estimated quantity of 584 tonnes of gastropods was landed in Kollam district during 2014 of which 97 per cent was from the Shakthikulangara fishing harbour and the Neendakara fishing harbour which registered an increase of 64 per cent compared to the previous year (CMFRI, 2015).

Babylonia zeylanica (whelks), Babylonia spirata, Turritella attenuata, Polystira sp., Crassispira sp. (screw shells), 
Architectonica perspective (staircase shell), Epitonium scalaris (ladder shells), Xenophora sp. (carrier shells), Tibia curta (True conchs), Natica albula, Natica lineata (Moon shells), Phalium glaucum, P. canaliculatum (Bonnet shells). Bursa spinosa (Frog), Tonna dolium (tun shells), Ficus ficus (fig shells), Rapana bulbosa (purples), Murex trapa, M. virgineus, M. badius, Murex sp., Hemifusus pugilinus, Fusinus toreuma (spindle shells), Oliva gibbosa, Oliva sp. (olive shells), Turbinella pyrum (sacred chank), Harpa conoidalis (harp shells), Conus glans and Conus sp. (cone shells) are the major species landed at the west coast of India (Philip and Appukuttan, 1995). It was found that B. zeylanica constitutes the lion's share of the edible gastropod landings in Shakthikulangara and Neendakara landing centres of Kollam, followed by $B$. spirata, and thus forms one of the targeted catches in these areas. Even though the molluscan production in India was comparatively insignificant during the earlier times, it climbed due to the increased demand for the edible as well as ornamental gastropods from around the globe coupled with their importance in generating an additional income as a bycatch. The total capture fishery production in the Asia-Pacific region is accounted as 40 million tonnes, out of which approximately 25 per cent is currently used for purposes other than human consumption (Shyam, et al., 2015). This highlights the equal footing of trade of ornamental gastropods alongside the edible gastropods in the economy.

The intertidal and inshore waters of Shakthikulangara Neendakara areas are inundated with gastropods, and are mainly used for meat and ornamental shells. Even though a significant number of gastropod exporting companies exist in this area, shell craft industries are lacking. Ornamental shells caught in these areas are typically traded to Tamil Nadu, Pondicherry, and Goa catering to numerous shell craft industries and small scale cottage industries.

B. zeylanica and B. spirata, commonly known as whelks, are the commercially important edible gastropods species available in Kollam. Numerous studies reported that the gastropods occur as a by-catch of shrimp trawlers from the Kollam area, with special reference to the whelk fishery (Philip and Appukuttan, 1995; Appukuttan and Philip, 1994).

\section{Material and methods}

\section{Location}

The study was conducted at the Shakthikulangara and Neendakara landing centres of Kollam district, Kerala, which is one of the major gastropod landing centres in the west coast of India, as well as the only one in Kerala.

\section{Data collection}

The study was carried out by using the primary data collected from the Shakthikulangara - Neendakara harbours and the local exporting companies. A semi- structured questionnaire which was later modified with necessary corrections was used for the field data collection. Major questions regarding the overall process of gastropod catch, species, quantum of trade, price level, seasonality, etc were posed to the respondents.

\section{Results and discussion}

According to the fishermen of Shakthikulangara - Neendakara region, the highest gastropod catch is reported during the third quarter of the year (July-September), followed by the second quarter (April-June). The catch is heavy when the sea bed moves due to the storms during these months. However, since the initiation of the trawl ban from June $15^{\text {th }}$, the fishermen are unable to utilize the opportunity at the fullest. The catch primarily consists of B. zeylanica $(60 \%)$ followed by B. spirata $(20 \%)$, as depicted in Fig. 1. The remaining 20 per cent consists of other species such as B. spinosa, Bursa margariticula, Tibia curta, etc.

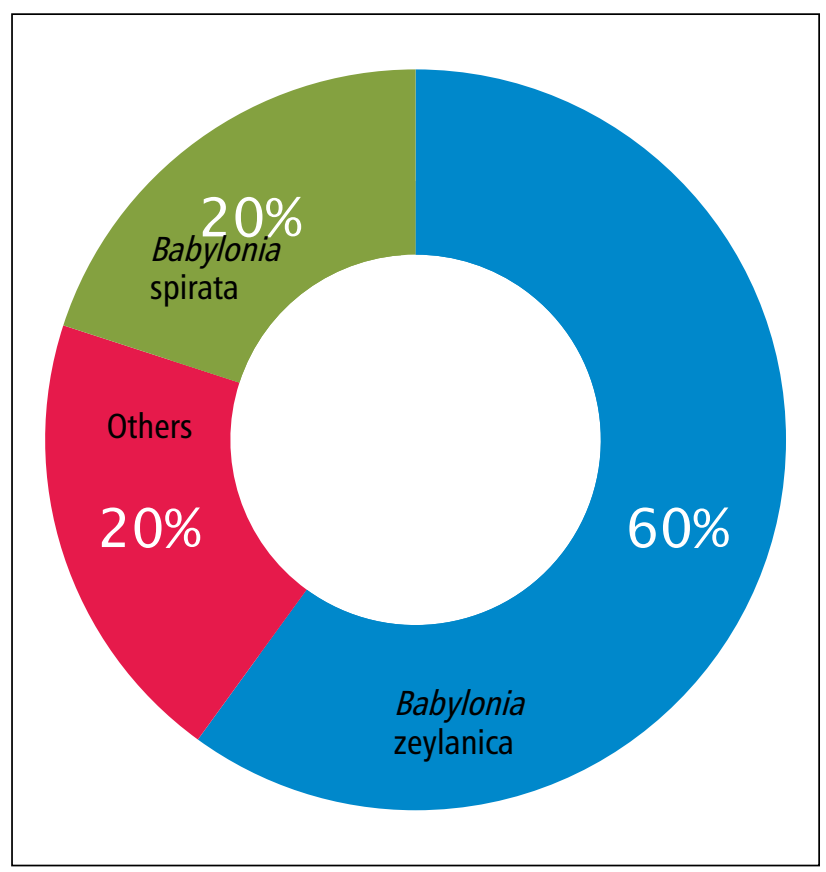

Fig. 1. The composition of Babylonia catch at the Kollam harbours

\section{Fishing operations}

Generally, on the basis of size, two categories of trawl boats such as 35 feet size and above 50 feet size are operate in targeted gastropod fisheries. Gastropod fishing is carried out by using a special type of net operated in a depth of 25-27 feet between 15-25 nautical miles as a single day trawl. The crew consists of a minimum of seven members.

\section{Cost and earnings}

The total operating expense for a single day trawl was found to be Rs. 25,000 , for which the fuel (diesel) expenses contributed 
96 percent followed by crew bata/provisions (4 percent). An average quantity of 400 litres of diesel is needed for a single day trawl of targeted gastropod catch. Almost $100-150 \mathrm{~kg}$ of gastropods is drawn in a haul. Each trawl boat does 7-8 hauls in a day and get an average catch of $800-1000 \mathrm{~kg}$ of gastropods.

The average price for Babylonia species at the landing centre is Rs. 90-135 per kg depending upon the size and variety of the species. The count wise average price at landing centre for Babylonia species is given in Table 1.

\begin{tabular}{ll}
\hline \multicolumn{2}{l}{ Table 1.Average price of gastropods ( Babylonia sp) at landing centres } \\
\hline Count per $\mathrm{Kg}$ & Average Landing centre price $(\mathrm{Rs} / \mathrm{kg})$ \\
\hline $30-50$ & 135 \\
\hline $50-80$ & 110 \\
\hline $80-120$ & 95 \\
\hline
\end{tabular}

\section{Crew wages and bata}

Crew wages are normally given on the basis of the revenue generated after sharing the cost of operation. Crew wages differ based on the type of craft and gear used. In the 35 feet trawl boat, the income after deducting the fuel, food and other expenses is divided equally between the crew members and the owner of the boat. In the above 50 feet category, there is a 60:40 division of the profit for the crew members and the owner of the boat respectively. Along with this, crew bata will be given as a daily wage irrespective of the catch. Crew bata also varies according to the craft and gear used and the duration of the fishing trip.

\section{Ratio analysis}

The ratio of average operating costs to the average gross earnings is the net profit or loss. Here labour productivity is expressed as the gross earnings per fisherman and capital productivity as the gross earnings per unit of capital invested. The value of catch or gross earnings per man-hour of effort or per trip show the efficiency or productivity of the fishing unit when it is in operation. Input output ratio is expressed as the cost of all inputs excluding the labour cost by the gross returns per trip. Based on the cost and earnings analysed, the following ratios had been worked out.

a Net operating income : Gross revenue-Total operating cost

$$
=1,01,250-25,000
$$$$
=76,250
$$

b Net profit

: Gross revenue-Total cost

$=1,01250-38,125$

$=63,125$

c Operating ratio

$$
\begin{aligned}
& : \frac{\text { (Total operating cost) }}{\text { (Gross returns per trip) }} \\
& =25,000 / 1,01250 \\
& =0.25
\end{aligned}
$$

d Labour productivity ratio: (Total catch)

(Crew size)

$=900 / 7$

$=128.5 \mathrm{~kg}$

e Input-Output ratio

: (Input costs(excluding labour) Gross revenue

$=24,000 / 1,01,250$

$=0.24$

f Profitability Ratio

: (Net profit) (Operating Cost)

$=38,125 / 25,000$

$=1.53$

g Net profit ratio

: (Net profit) (Gross revenue)

$=38,125 / 1,01,250$

$=0.38$

\section{Gastropod Utilisation}

The gastropod, once considered as a bycatch of the shrimp landing has become a major commercial activity in the landing centres of Kollam district. The increased demand for the polished shells, the curios and other trinkets made out of molluscan shells from around the world had set the starting of a number of cottage industries for shell crafting and gastropod exporting and it also created a lot of job opportunities in turn. Apart from being a major contributor of trade and revenue, the handicraft industries favour numerous people. Many fishermen families are involved in the collection and supply of gastropod shells as a part time job.

Apart from the shell and meat, the operculum of certain gastropods is in immense demand from various part of the world. The dried operculum is used as an important raw material by Chinese and Japanese incense makers. There is a huge international market for operculum trade with the price ranging from US \$ 7-9 to US \$ 44-44.5/kg (Sujit and Deshmukh, 2013). India ranks among the major exporters of high quality dried operculum.

\section{Gastropod Trade}

The molluscan shells are used for a variety of purposes. It is also used as a raw material for many calcium carbonate based industries apart from handicraft and shell craft industry. Several cottage industries in South India produce curios and other decorative objects by making use of the gastropod shells. The polished and modified shells as well as shell crafts are in high demand across the globe.

About 15 exporting companies specialising in gastropod trade are located around the Shakthikulangara - Neendakara landing centres. The gastropod landings are obtained by the exporting companies from the landing centre itself and the species are 
separated and weighed onsite. The gastropods are taken to the nearby exporting companies where they are cleaned and processed. No middlemen work in between the fishermen and the exporting companies. Fig. 2 and 3 depicts the gastropods being carried for weighing at the landing centre and set ready for weighing, respectively.

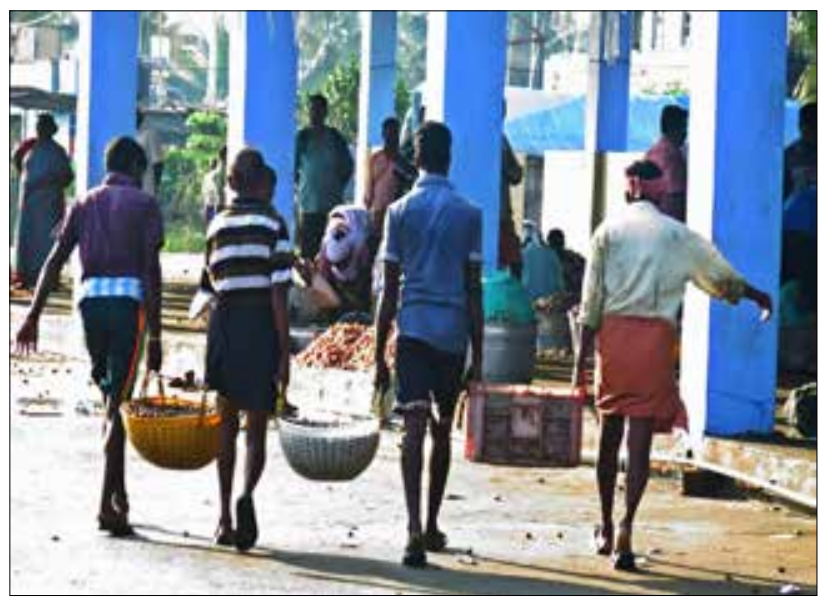

Fig.2. Gastropods carried to the weighing centre

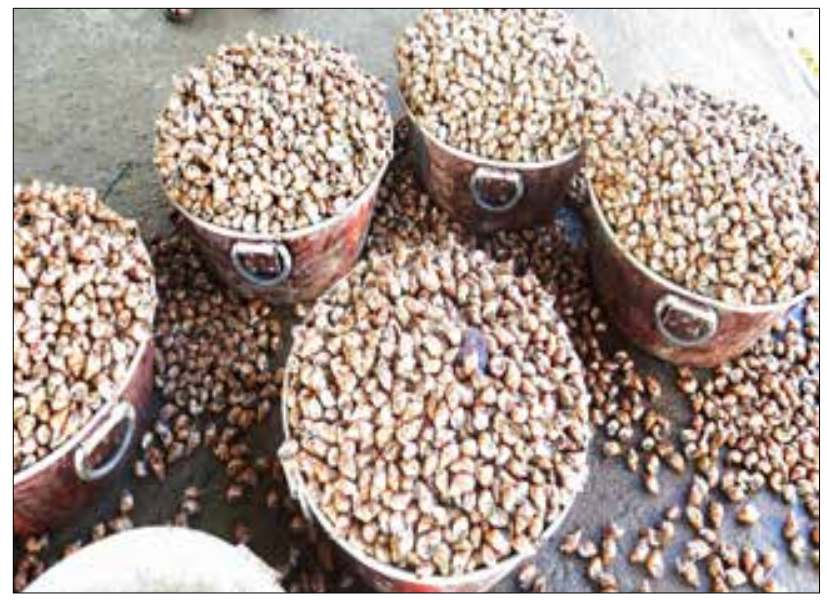

Fig.3. Gastropods set ready to get weighed

Either live or frozen gastropod is exported to various regions around the globe, at an average price ranging from of $\$ 2.3$ $\$ 3.8$ per $\mathrm{kg}$. Gastropods for export as a whole are cleaned and washed several times in water and the processed gastropods are packed in bags totalling $30 \mathrm{~kg}$ each. One kilo of gastropods will yield almost 200-300 grams of meat. However, nowadays the gastropod meat exporting companies are rare. The companies were exporting frozen meat and the remaining shells were sent to various shell craft industries in Tamil Nadu, Pondicherry and Goa. But now, these companies are concentrated in exporting the whole gastropod either frozen or alive. The B. zeylanica, which is landed in huge quantities in the Kollam harbours are the main frozen gastropod and are exported at an average rate of $\$ 2.3$ per $\mathrm{kg}$, whereas Babylonia spirata is exported alive at a price ranging up to $\$ 3.8$ per $\mathrm{kg}$. Fig. 4 shows a gastropod exporting company in Kollam.

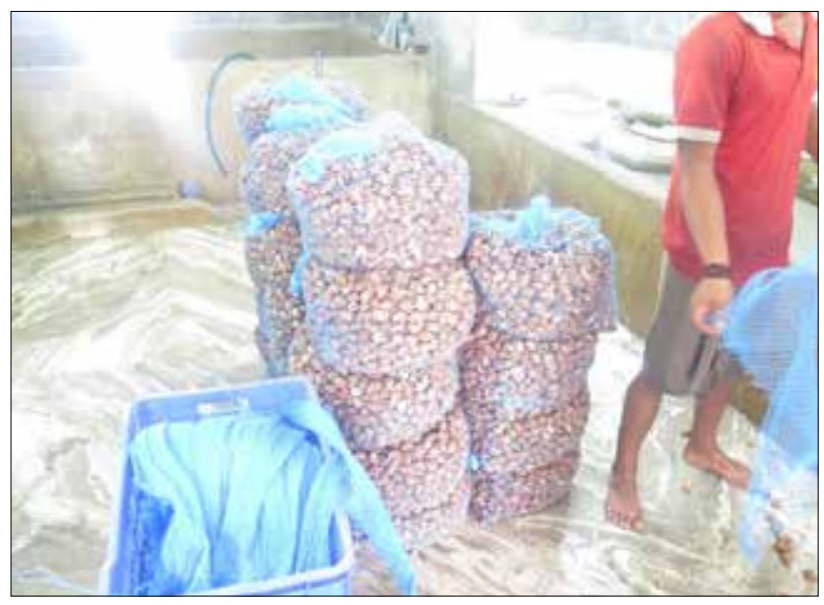

Fig.4. Gastropods washed and packed at an exporting company of Kollam

The ornamental gastropod is an emerging resource in Indian seas. However, as no shell crafting firms are located in Kerala, the shells are usually sent to the shellcraft industry in Tamil Nadu, Pondicherry, and Goa. The gastropod shell are used to make attractive models, garlands, studs, rings, bangles, paper weights, curios, ash trays, door and window curtains, sacred chanks, bathi stands, lamp shades, key chains, etc. The curios and other trinkets made out of shells are expensive articles as they have great demand in the home as well as foreign markets. The value chain analysis of gastropod is given in Fig. 5 .

According to the study, the species $B$. spirata is an important item of export since the early 1993. Initially the export was mainly to Japan, and has now expanded to China, Malaysia, France, U.S. and countries in the Gulf regions. The price of the gastropods depends upon the species, quality and availability. India ranks

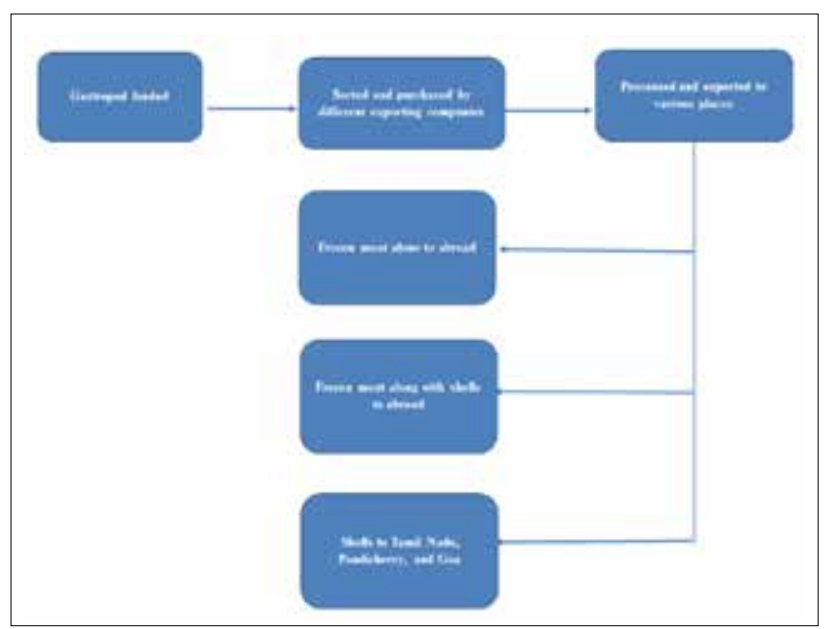

Fig.5. Value chain analysis of commercial gastropod trade 
among the major exporters of dried operculum, which is used as a scent fixative by the incense makers of China and Japan (Sujit and Deshmukh, 2013). The operculum of the Babylonia species, which is the major gastropod landed of Kollam, is the highest priced one.

The gastropods trade offers considerable revenue by export earnings. The shell craft industry has to be uplifted as scope exists for it to progress as a profitable industry. The increased demand for the operculum of gastropods from Chinese and Japanese incense makers is also considered to be a golden opportunity for the exporting industries.

Significantly, the quantum of gastropod landed over the years had increased. Even though molluscs are able to withstand fishing pressure because of their high fecundity, reproductive capacities and planktonic larval life, cases of depletion of stock has been reported due to large-scale exploitation for commercial purposes combined with pollution, and environmental hazards (Appukuttan, 1996). Intensive trawling along the whelk beds may lead to extensive destruction of egg and juveniles there by affecting recruitment. Inshore trawling as well as exploitation of undersized gastropods has to be restricted to protect the resource. Hence appropriate measures have to be undertaken immediately to protect it as a resource.

\section{Acknowledgements}

The authors express their gratitude to Director, CMFRI, for funding the institutional projects which paved way for publishing the paper. The authors are also grateful to the unknown reviewer for suggesting improvements in the paper.

\section{References}

Appukuttan, K. K.1996. Marine molluscs and their conservation. In. N.G. Menon and C.S.G. Pillai. (Eds.). Marine Biodiversity Conservation and Management. Central Marine Fisheries Research Institute, Cochin,

Appukuttan, K. K. and M.Babu Philip.1994. Gastropods - An emerging resource in the by catch of shrimp trawlers at Sakthikulangara - Neendakara area. Seaf Export J., $25(2): 5-17$

Babu Philip, M. and K. K. Appukuttan. 1995. A check list of gastropods landed at Sakthikulangara - Neendakara area. Mar. Fish, Inf. Serv., T\& E. Ser., 138: 9-10

CMFRI 2015. Annual Report 2014-15. Central Marine Fisheries Research Institute, Cochin. $279 p$

Hornell, J.1909. Report to the Government of Baroda on the marine zoology of Okhamandal in Kattiawar, Williams and Norgate, London, $1 \mathrm{pp}$.

Hornell, J. 1949. The study of Indian molluscs (part II). J Bombay Nat. Hist. Soc., 48(3): $543-569$.

Hornell, J.1951. Indian molluscs. J Bombay Nat Hist. Soc., 1-96, pl+1.

Shyam, S Salim, M. Rahman Ramees and Antony Bindu. 2015. Sardine economy of Kerala: Paradigms and Perspectives. Int. J. Fish. Aqua. Stud., 2 (6): 351-356.

Sujit Sundaram and V.D., Deshmukh, 2013. Gastropod operculum - A Unique Trade. Mar Fish. Infor. Serv T and E Ser., 217: pp. 20 